\title{
The impact of the recent AAP changes in palivizumab authorization on RSV-induced bronchiolitis severity and incidence
}

\author{
Antonino Capizzi ${ }^{1}$, Michela Silvestri ${ }^{1}$, Andrea Orsi $^{2}$, Renato Cutrera ${ }^{3^{*}} \mathbb{D}$, Giovanni A. Rossi ${ }^{1}$ and Oliviero Sacco ${ }^{1}$
}

\begin{abstract}
Following the most recent modification by the American Academy of Pediatrics, based on American studies on RSV epidemiology, the Italian Drug Agency (AIFA) decided to limit the total financial coverage of the palivizumab prescription by the National Health Service only to the $<29$ WGA group and age $\leq 12$ months at the beginning of the RSV epidemic season. However, the vulnerability of otherwise healthy premature infants $\geq 29$ wGA has been demonstrated in Italian analyses. We retrospectively reviewed records from children $\leq 1$ years of age admitted for RSV-induced ALRI at the Gaslini Hospital, over three consecutive RSV epidemic seasons (RES) (2014-2017). We found that the prescription limitation on RSV immunoprophylaxis in preterms was associated in the 2016-2017 RES with: a) a high proportion of admission for the $<36$ wGA infants, the great majority born at 33- <36 wGA and a chronological age of $<6$ months; b) a high proportion of preterms treated with high flow nasal cannula ventilation. These results strongly point to a need to reevaluate the role of palivizumab prophylaxis in the $>=29$ wGA subpopulation when specific risk factors are present.
\end{abstract}

Keywords: Palivizumab, Respiratory syncytial virus, Prophylaxis, Preterm

\section{Dear Editor,}

Respiratory syncytial virus (RSV) is the single most important cause of acute lower respiratory tract infection (ALRI) in infants, associated with significant morbidity and, sometimes, mortality in industrialized nations [1]. In clinical trials, palivizumab reduced RSV hospitalization rates for premature infants [1]. The current Italian Guidelines recommend palivizumab prophylaxis for infants of 29-35 weeks gestational age (wGA) and a chronological age $\leq 6$ months at the beginning of the epidemic season, in presence of risk conditions predisposing the infant to severe infections and/ or need for hospitalization [2]. These include attendance of the child in a community setting and/or presence of one or more cohabitees younger than 5 years [3]. However, following the most recent modification by the American Academy of Pediatrics based on American studies on RSV epidemiology [4], in September 2016, the Italian Drug Agency (AIFA) decided the total financial coverage of the palivizumab prescription to

\footnotetext{
* Correspondence: renato.cutrera@opbg.net

${ }^{3}$ Pediatric Pulmonology and Sleep \& Long Term Ventilation Unit, Pediatric

Hospital "Bambino Gesù", Rome, Italy

Full list of author information is available at the end of the article
}

the healthy preterms by the National Health Service, should be limited to the $<29$ wGA group and age $\leq$ 12 months at the beginning of the RSV epidemic season (RES) [5]. However, the vulnerability of otherwise healthy premature infants, and most notably in the $<32$ wGA category was demonstrated by an Italian retrospective analysis on RSV-associated hospitalization during the RSV epidemic season, over a 4 year period, when the use of prophylaxis palivizumab was not widespread in premature infants [6]. Moreover, a recent study on total costs for hospitalizations and emergency room and/or outpatient visits in infants in the first 3 years of life in Lombardy (Italy) showed that extending palivizumab prophylaxis to 29-32 wGA infants appeared to be a cost-effective strategy [7]. With this background we retrospectively reviewed records from children $\leq 1$ years of age admitted, for RSV-induced ALRI at the Gaslini Hospital, over three consecutive RES (2014-2017) (Fig. 1). The possible impact on the incidence and severity of RSV bronchiolitis after the new prescription limitation was evaluated, comparing the third RES (2016-2017), with the two previous ones.

All the infant included in the study, had a nasal swab positive for RSV. Co-infections were detected 

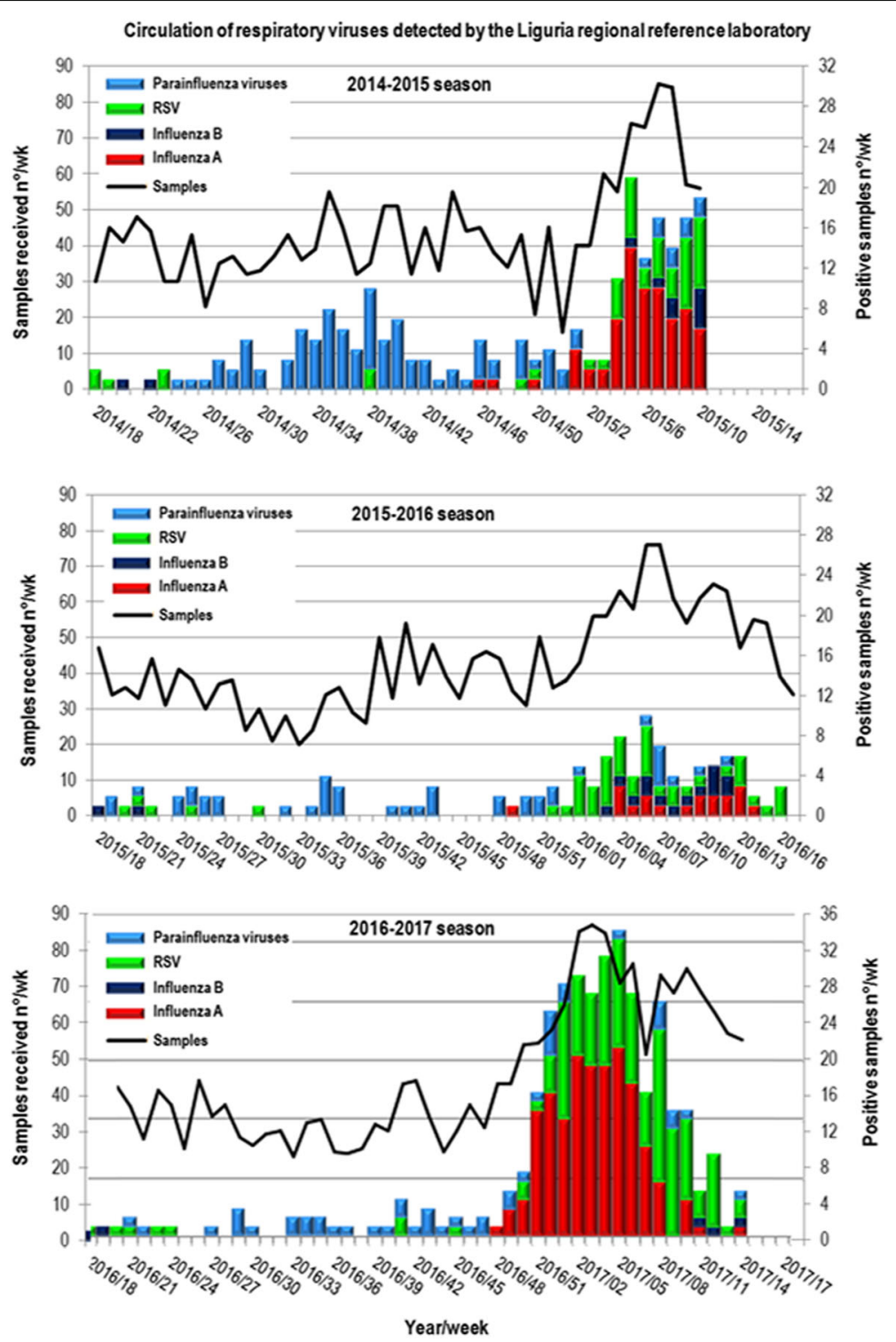

Fig. 1 Circulation of respiratory viruses detected by the Liguria regional reference laboratory in the three RSV epidemic seasons (2014-2015, 2015-2016 and 2016-2017): data related to RSV are reported in green columns

only in 4 infants (Haemophilus influenza) with a wGA $<34$ weeks. The total number of infants admitted for RSV-induced ALRI in the three RSV epidemic seasons was 366: 137 in the 1 th, 109 in the 2 nd and 120 in the 3rd season (Fig. 2a). Only $7.7 \%$ of these infants were preterms $(29-<36 \mathrm{wGA}), 6.6 \%$ in the $33-<36$ wGA subgroup and only $1.1 \%$ in the $29-<33$ wGA subgroup. Interestingly, the proportion of preterms admitted tended to increased in the three RES from $6.6 \%$, to $7.3 \%$, and to $9.2 \%$, respectively, for the $29-<36$ wGA group (Fig. 2b), and from $5.1 \%$ to $6.4 \%$ and to $8.3 \%$, respectively, for the $33-<36$ wGA subgroup (Fig. 2c). Due to the due to small sample size these increases are not statistically significant. The proportion of the very young infants admitted with a chronological age of $<6$ months tended to increase in the three RSV epidemic seasons from $77.4 \%, 71.6 \%$ and $80.8 \%$ (Fig. 3a), and this tendency was even more evident in the $<3$ months chronological age group (48.2\%, to $54.1 \%$ and to $63.3 \%$, respectively (Fig. 3b).

This trend was observed also in preterms admitted with a chronological age of $<6$ months $(66.7 \%, 50 \%$ and $81.8 \%$, respectively; Fig. $3 \mathrm{c}$ ) and in the $<3$ month subgroup (55.6\%, 50\% and $81.8 \%$, respectively (Fig. $3 \mathrm{~d}$ ).

The vast majority of the 33- $<36$ wGA infants had a chronological age of $<6$ months at the beginning of the 

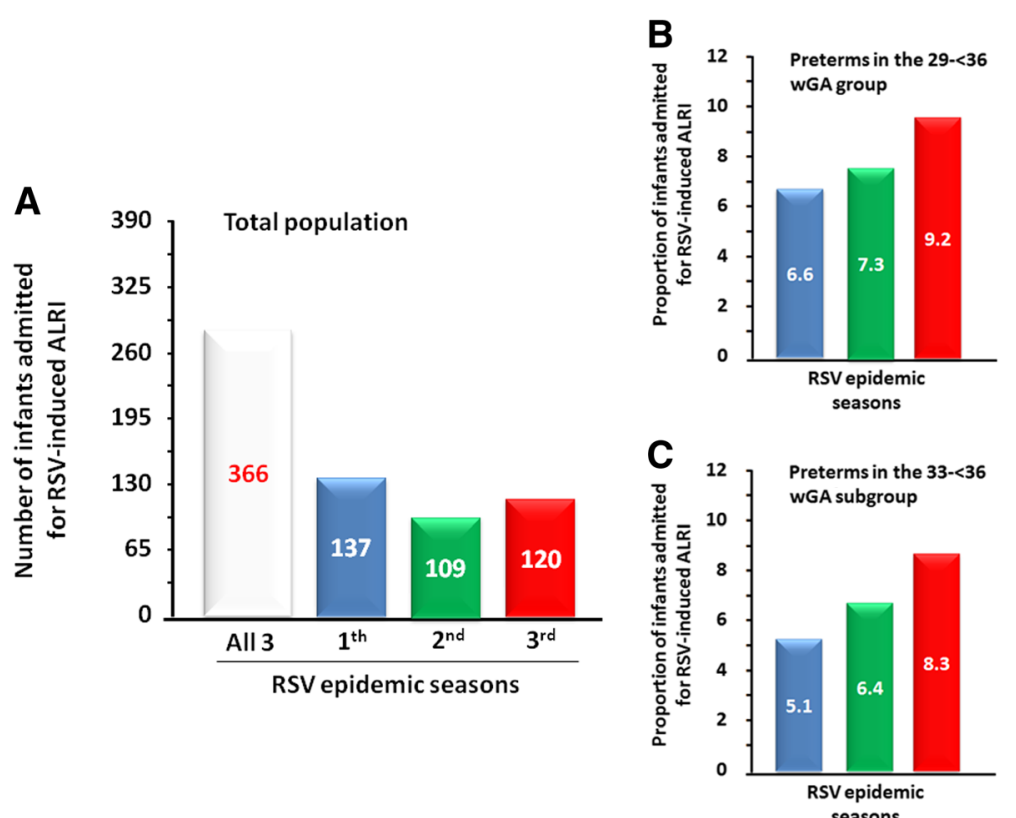

Fig. 2 Admission for RSV infection in infants. a Number of infants admitted in the three RSV epidemic seasons (2014-2015, 2015-2016 and 20162017). b Proportion of preterms (29- <36 wGA) admitted in each RSV epidemic season. c Proportion of preterms (33-<36 wGA) admitted in each RSV epidemic season

RSV epidemic season and had at least one risk factor [3]. In addition, $64 \%$ of the admitted < 36 wGA infants were treated with high flow nasal cannula (HFNC) ventilation: $50 \%$ of those born at $29-<33$ wGA and $66.6 \%$ of those at $33-<36$ wGA. In the three RSV epidemic seasons, the proportion of preterms treated with HFNC ventilation was $77.8 \%, 25.0 \%$ and $81.8 \%$, respectively (Fig. 4a), the numbers being 5, 2, 9 in the $33-<36$ wGA subgroup (Fig. 4c).

Therefore, the prescription limitation on RSV immunoprophylaxis in preterms was associated in the 20162017 RSV epidemic season with: a) a high proportion
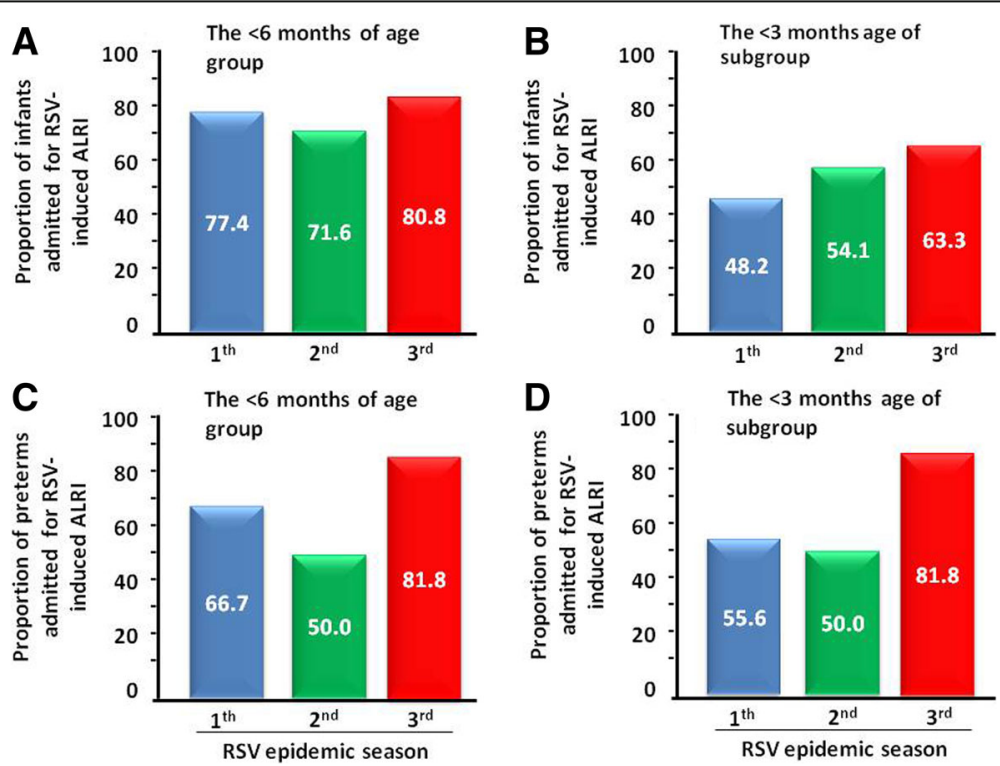

Fig. 3 Proportion of infants (panel $\mathbf{a}$ and $\mathbf{b}$ ) or of preterms (panel $\mathbf{c}$ and $\mathbf{d}$ ) admitted for RSV infection in the three RSV epidemic seasons (2014-2015, 2015-2016 and 2016-2017). a and $\mathbf{c}$ Infants < 6 months of age; (b and $\mathbf{d}$ ). Subgroup of infants $<3$ months of age 


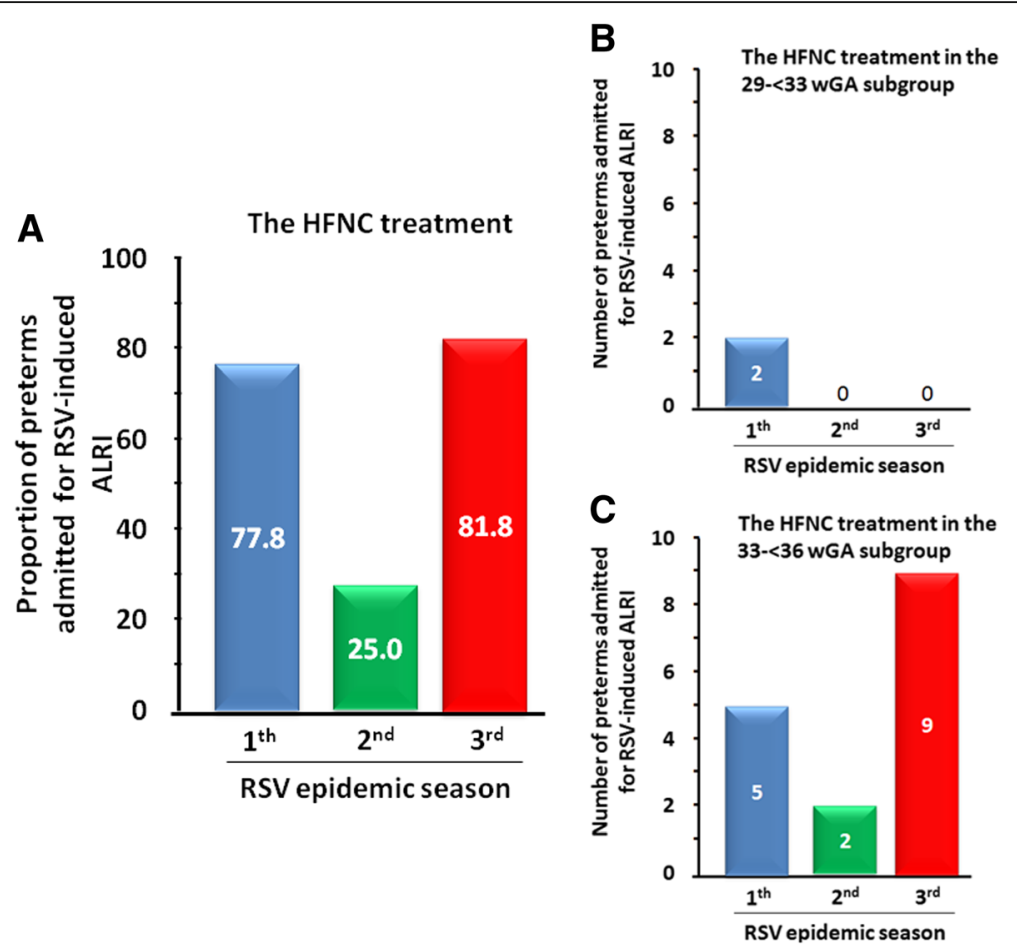

Fig. 4 Frequency of treatment with high flow nasal cannula (HFNC) ventilation among preterms in the three RSV epidemic seasons (2014-2015, 2015-2016 and 2016-2017). a Whole preterm population. b The 29-<33 wGA subgroup. c The 33-<36 wGA subgroup

of admission for the $<36 \mathrm{wGA}$ infants, the great majority born at 33- $<36$ wGA and with chronological age of $<6$ months; b) a high proportion of preterms treated with HFNC ventilation, mostly in the at $33-<36$ wGA subgroup. The major limitation of the study is that, since the data were collected in a single tertiary level paediatric hospital, the numbers of preterm infants was very small, precluding a reliable statistical analysis. This is a common problem in these kind of reports since preterms represent only a very small proportion in the general infant population, as shown also in studies that have been cited by the American Academy of Pediatrics in the guidance for palivizumab prophylaxis $[8,9]$. Data collection on national records involving other tertiary level paediatric hospitals could provide a sample size large enough to perform a reliable statistical analysis. However, our results on RSV hospitalization and HFNC treatment clearly highlight the vulnerability of young preterms, especially in this last RSV season and point to a need to reevaluate the role of palivizumab prophylaxis in the $>29$ wGA subpopulation when specific risk factors are present.

\section{Acknowledgements}

Not applicable.

\section{Funding}

The authors declare that they have not received any funding for this analysis.
Availability of data and materials

Data are not available for free access.

\section{Authors' contributions}

All the authors equally contributed in collecting, analyzing, interpreting data and in writing the manuscript. All the authors read and approved the final manuscript.

Ethics approval and consent to participate Not applicable.

\section{Consent for publication}

Not applicable.

\section{Competing interest}

$A C, A O$, OS declare that they have no competing interests, MS and GAR served as a consultant for AbbVie S.r.l.

\section{Publisher's Note}

Springer Nature remains neutral with regard to jurisdictional claims in published maps and institutional affiliations.

\section{Author details}

'Department of Pediatrics, Pulmonology and Allergy Unit and Cystic Fibrosis Center, Istituto Giannina Gaslini, Genoa, Italy. ${ }^{2}$ Department of Health Sciences, Hygiene Unit, IRCCS University Hospital San Martino Polyclinic, Genoa, Italy. ${ }^{3}$ Pediatric Pulmonology and Sleep \& Long Term Ventilation Unit, Pediatric Hospital "Bambino Gesù", Rome, Italy. 
Received: 30 May 2017 Accepted: 3 August 2017

\section{Published online: 14 August 2017}

\section{References}

1. Hall CB, Weinberg GA, Iwane MK, Blumkin AK, Edwards KM, Staat MA, et al. The burden of respiratory syncytial virus infection in young children. N Engl J Med. 2009;360(6):588-98.

2. Bollani L, Baraldi E, Chirico G, Dotta A, Lanari M, Del Vecchio A, et al. Revised recommendations concerning palivizumab prophylaxis for respiratory syncytial virus (RSV). It J Ped. 2015;41:97.

3. Baraldi E, Lanari M, Manzoni P, Rossi GA, Vandini S, Rimini A, et al. Intersociety consensus document on treatment and prevention of bronchiolitis in newborns and infants. Ital J Pediatr. 2014:40:65.

4. American Academy of Pediatrics Committee on Infectious Diseases, American Academy of Pediatrics Bronchiolitis Guidelines Committee. Updated guidance for palivizumab prophylaxis among infants and young children at increased risk of hospitalization for respiratory syncytial virus infection. Pediatrics. 2014;134(2):e620-38.

5. Gazzetta Ufficiale della Repubblica Italiana. GU Serie Generale n.221 del 21-9 2016. http://www.gazzettaufficiale.it/eli/gu/2016/09/21/221/sg/pdf. Accessed 10 Aug 2017.

6. Silvestri M, Marando F, Costanzo AM, di Luzio PU, Rossi GA. Respiratory Syncytial virus-associated hospitalization in premature infants who did not receive palivizumab prophylaxis in Italy: a retrospective analysis from the Osservatorio study. Ital J Pediatr. 2016;42:40.

7. Zuccotti GV, Fabiano V. Indications to respiratory syncytial virus immunoprophylaxis in the 29-32 wGA group: is there still room for debating? Ital J Pediatr. 2017;43:17.

8. Stevens TP, Sinkin RA, Hall CB, Maniscalco WM, McConnochie KM. Respiratory syncytial virus and premature infants born at 32 weeks' gestation or earlier: hospitalization and economic implications of prophylaxis. Arch Pediatr Adolesc Med. 2000;154:55-61.

9. Hall CB, Weinberg GA, Blumkin AK, Edwards KM, Staat MA, Schultz AF, et al. Respiratory syncytial virus-associated hospitalizations among children less than 24 months of age. Pediatrics. 2013;132:e341-8.

\section{Submit your next manuscript to BioMed Central and we will help you at every step:}

- We accept pre-submission inquiries

- Our selector tool helps you to find the most relevant journal

- We provide round the clock customer support

- Convenient online submission

- Thorough peer review

- Inclusion in PubMed and all major indexing services

- Maximum visibility for your research

Submit your manuscript at www.biomedcentral.com/submit 